\title{
O modelo instrucional 5E e o ensino de Química: definições e estratégias
}

\author{
The 5E instructional model and the teaching of Chemistry: definitions and strategies \\ El modelo de instrucción 5E y la enseñanza de la Química: definiciones y estrategias
}

Recebido: 12/12/2021 | Revisado: 18/12/2021 | Aceito: 21/12/2021 | Publicado: 03/01/2022

\author{
Sanley Viegas Soares \\ ORCID: https://orcid.org/0000-0002-3080-5577 \\ Universidade Federal do Maranhão, Brasil \\ E-mail: sanley.viegas@discente.ufma.br \\ Cícero Wellington Brito Bezerra \\ ORCID: https://orcid.org/0000-0001-9058-9469 \\ Universidade Federal do Maranhão, Brasil \\ E-mail: cwb.bezerra@ufma.br
}

\begin{abstract}
Resumo
A crise sanitária mundial trouxe desafios para a sociedade como um todo e para a educação em particular. A abordagem EAD, ainda longe da admiração e da unanimidade dos educadores, passou a ser apresentada com solução emergencial durante o contexto da pandemia, e todos os professores foram convocados a, de algum modo, se envolver com as estratégias desta modalidade de ensino. Hoje, o uso das tecnologias digitais da informação e comunicação no contexto escolar é uma realidade inconteste em todos os níveis de escolarização, o que vem provocando alterações significativas no modus operandi do sistema educacional e das rotinas de professores e alunos. Rompem-se, cada vez mais, as barreiras entre os espaços físico e virtual e, acompanhando a escalada tecnológica, redefinem-se meios para conduzir, aprender, interagir, criar e de estabelecer relações entre professores e alunos, bem como entre os próprios estudantes. A sala de aula não é mais a mesma e, sem intenção de profetismo, talvez não volte a ser exatamente o que era. Esse trabalho foi realizado durante os dias críticos iniciais da pandemia em escolas privadas de São Luís (MA), durante aulas de Química no Ensino Médio, e busca ressaltar a importância e a potencialidade do método instrucional 5E (Engaje, Explore, Explain, Elaborate, Evaluation) para um ensino e aprendizagem motivadores. A metodologia empregada foi de natureza qualitativa e a coleta dos dados aconteceu por meio da observação durante as aulas ministradas.
\end{abstract}

Palavras-chave: Ensino híbrido; Química; Método 5E; Ensino de ciências.

\begin{abstract}
The global health crisis brought challenges to society as a whole and to education in particular. The distance learning approach, still far from the admiration and unanimity of educators, started being presented as an emergency solution during the pandemic context, and all teachers were called upon to somehow get involved with the strategies of this teaching modality. Today, the use of digital information and communication technologies in the school context is an undeniable reality at all levels of schooling, which has caused significant changes in the modus operandi of the educational system and the routines of teachers and students. The barriers between physical and virtual spaces are increasingly being broken down and, following the technological escalation, the means to conduct, learn, interact, create, and establish relationships between teachers and students, as well as between the students themselves, are being redefined. The classroom is no longer the same, and, without wishing to be prophetic, it may never be exactly what it was. This work was carried out during the initial critical days of the pandemic in private schools in São Luís (MA), during high school chemistry classes, and seeks to highlight the importance and potential of the 5E instructional method (Engage, Explore, Explain, Elaborate, Evaluate) for motivating teaching and learning. The methodology used was qualitative in nature and data collection was carried out through observation during the classes. Keywords: Hybrid education; Chemistry; 5E Method; Science education.

\section{Resumen}

La crisis sanitaria mundial planteó retos a la sociedad en su conjunto y a la educación en particular. El enfoque de la EAD, aún lejos de la admiración y la unanimidad de los educadores, comenzó a presentarse como una solución de emergencia durante el contexto de la pandemia, y todos los profesores fueron llamados a involucrarse de alguna manera con las estrategias de esta modalidad de enseñanza. Hoy en día, el uso de las tecnologías digitales de la información y la comunicación en el contexto escolar es una realidad innegable en todos los niveles educativos, lo que ha provocado cambios significativos en el modus operandi del sistema educativo y en las rutinas de profesores y alumnos. Las barreras entre los espacios físicos y virtuales se rompen cada vez más y, tras la escalada tecnológica, se redefinen los medios para conducir, aprender, interactuar, crear y establecer relaciones entre profesores y alumnos, así
\end{abstract}


como entre los propios alumnos. El clase ya no es la misma y, sin ánimo de profetizar, puede que no vuelva a ser exactamente lo que era. Este trabajo fue realizado durante los días críticos iniciales de la pandemia en las escuelas privadas de São Luís (MA), durante las clases de química de la escuela secundaria, y busca resaltar la importancia y la potencialidad del método de instrucción 5E (Engage, Explore, Explain, Elaborate, Evaluate) para una enseñanza y aprendizaje motivadores. La metodología utilizada fue de carácter cualitativo y la recogida de datos se realizó mediante la observación durante las clases.

Palabras clave: Educación híbrida; Química; Método 5E; Educación científica.

\section{Introdução}

Uma das características do ensino regular tradicional é a maneira como se organiza o espaço da sala de aula. Embora a diversidade de modelos experienciados, dos mais inovadores e disruptivos aos incrementais e mais tecnológicos (virtuais), a configuração tradicional manteve-se dominante: alunos enfileirados e professor em destaque, em conformidade com modelo pedagógico adotado (Moran, 2014). Da educação infantil à pós-graduação permaneceu o mesmo arranjo, ressaltando a marca do fordismo, sempre com destaque para a figura do professor, o protagonista do processo, e com as cadeiras enfileiradas com expectadores nem sempre ativos e atentos (Basso, 2017).

Mas, diante do cenário atual imposto pela pandemia, propiciando um distanciamento físico em larga escala, percebeuse, de forma mais intensa e generalizada, a necessidade de se rever o espaço e as interações necessários ao processo educacional. Esta experiência coletiva de ensino remoto, em alguns casos híbridos, vem quebrando as barreiras entre os espaços físico e digital e provocando mudanças nas concepções mais conservadoras sobre local, metodologias e tempo de aprendizagens. Notadamente espera-se por um fortalecimento cada vez maior do uso das ferramentas digitais e dos ambientes virtuais na educação, tanto pelo fato dos professores terem se permitido a tarefa de experimentá-los, quanto pelo apelo que provocam nos jovens estudantes, fascinados, a maioria, pela linguagem tecnológica. Mas, é o ensino híbrido um mal necessário momentâneo, um simples plano de contingência, ou esta modalidade veio para ficar e apresenta contribuições positivas ao processo de formação dos alunos? Quais as vantagens e fragilidades desta modalidade em relação ao ensino tradicional, mais especificamente ao ensino da Química? São questões pertinentes e motivadoras do trabalho docente comprometido.

Segundo (Beck, 2017) "a aprendizagem é um processo contínuo e dinâmico que ocorre durante toda a vida do ser humano e é por meio dela que o indivíduo se apropria de algo novo, aprende um novo conhecimento, de modo que esse conhecimento passa a fazer parte dele.” Por esta definição, a aprendizagem prescinde do espaço físico e da presença constante de um professor. Em outras palavras, não é necessário conduzir-se sempre ao mesmo ambiente e ter instruções de um professor em tempo real para alcançar a aprendizagem. Isto, no nosso entendimento, não diminui a importância da escolarização. Ao contrário, acresce-lhe responsabilidades, já que necessita desenvolver competências nos alunos para a conquista da autonomia, da capacidade empreendedora e da independência intelectual (Silva et al, 2020). Embora a polissemia da palavra competência, ela está sendo aplicada aqui no sentido de mobilização de saberes e de recursos cognitivos para além da técnica e do saberfazer para as situações cotidianas. Competência no sentido de atribuição de significados aos saberes, da tomada de decisões pautada na reflexão, na autonomia e no pensamento crítico (Silva, 2008). Competência, portanto, é mais que conhecimento e conjunto de habilidades, é a capacidade desenvolvida para o enfrentamento de demandas complexas, em um contexto específico, envolvendo saberes, atitudes e valores em situações reais.

O uso das tecnologias digitais da informação e comunicação (TDIC) no contexto escolar não apenas substitui o espaço físico provendo plataformas para interações remotas e em tempo real. Há todo um ambiente voltado para a aprendizagem com recursos e funcionalidades que vão além de um simples meio ou suporte para uma exposição oral de conteúdos. Chats, enquetes, vídeos, compartilhamento de documentos e material didáticos, por exemplo, tudo para que o professor transponha o seu discurso e interaja (de forma síncrona ou não) com seus estudantes, permitindo-os participar do processo de forma mais direta, a exemplo das metodologias ativas. 
Nesse sentido, os conhecimentos e as percepções dos estudantes devem ser considerados e ampliados, para que a parceria entre ambos, professor e estudante, seja eficaz. O professor, por meio das plataformas digitais, pode favorecer conexões das diversas informações que chegam a todo o momento para os estudantes, transformando essas informações em conhecimentos e esses conhecimentos em experiências, através de práticas. Então, o professor exerce durante todo o processo de ensino-aprendizagem o papel de facilitador, provocador e estimulador do interesse dos estudantes, desempenhando o papel de mediador e disseminador do conhecimento e não de detentor. Isto porque vivemos numa sociedade que passa por várias transformações e o professor contribui com seu conhecimento e sua experiência, tornando os estudantes mais críticos e criativos para tomadas de decisões em seu cotidiano. Toda essa transformação na sociedade é voltada para o ensino dialógico, uma vez que os seres humanos aprendem interagindo uns com os outros, formando o processo aprender a aprender.

Para que o processo de aprendizagem ocorra, é necessário desenvolver percepções sobre quais as motivações, necessidades, vontades, desejos, ambições, etc. Isso tudo contribuirá em nosso modo de aprender, seja ele dentro ou ultrapassando as paredes da sala de aula. Levando em consideração todos os aspectos relacionados ao processo de ensinoaprendizagem, este trabalho tem como objetivo geral fazer uma verificação entre o ensino tradicional e a metodologia ativa ensino-híbrido, comparando o rendimento dos estudantes, indicando as contribuições das metodologias abordadas na construção do conhecimento. A pesquisa é de natureza qualitativa, foi motivada pelo fato de que a aprendizagem é construída pelo estudante e não pela transmissão do professor.

No uso das metodologias ativas o estudante é visto como um sujeito ativo, envolvido de forma mais intensa em seu processo de aprendizagem, criando autonomia e possibilitando a agilidade e a personalização das experiências de aprendizagem. Algumas pesquisas apontam as metodologias ativas como contraponto do ensino tradicional centrado no ensino. Diante disso, para adotar as metodologias ativas é necessário entender o processo de aprendizagem e valorizar as experiências vividas pelo estudante.

\subsection{As metodologias ativas de aprendizagem}

Talvez no tempo de escassez de livros, revistas e de outras fontes de informação, o estudante necessitasse memorizar e reproduzir conteúdos, bem como o professor atuar como fonte única da informação escolar. Hoje os tempos são outros e os novos desafios exigem do estudante outras competências, as quais são desenvolvidas pelo seu esforço contínuo de construir seu próprio conhecimento, com ações que ultrapassem leituras e memorizações. Neste ensino, deve-se valorizar a capacidade de pensar e agir dos estudantes, o seu contexto de vida, a interação teoria e prática, a devida problematização dos conteúdos e a resolução de situações problemas que estão presentes no seu cotidiano.

As metodologias são "[...] diretrizes que orientam os processos de ensino e aprendizagem, que se concretizam em estratégias, abordagens e técnicas concretas, específicas e diferenciadas" (Moran, 2018, p. 4). Nesse rumo, pode-se dizer que existem várias metodologias que foram construídas ao longo da história educacional, tendo características próprias de seu tempo, podendo ter influenciado as práticas. Atualmente é muito discutido o termo metodologias ativas, ao que se destaca a necessidade de se compreender em qual sentido é utilizado. Em (Moran, 2018, p. 4), encontra-se que as metodologias ativas “[...] dão ênfase ao papel de protagonista do aluno, ao seu envolvimento direto, participativo e reflexivo em todas as etapas do processo". O autor menciona que o processo de aprendizagem ativa acontece desde o nascimento do ser humano e ao longo da sua vida em várias etapas e processos a partir de situações concretas e reais.

Porém, já existe uma inovação que tem provocado mudanças consideráveis na forma de aprender e pensar dos estudantes. Essa inovação vem acompanhada da adoção de um conjunto de metodologias ativas que permitem estudantes e professores assumirem o protagonismo de sua aprendizagem. Portanto, as metodologias ativas são técnicas, estratégias, abordagens e perspectivas de aprendizagem individual e colaborativa que envolve e engaja os estudantes no desenvolvimento 
de projetos e/ou atividades práticas. Nos contextos em que são adotadas, o estudante é visto como um ser ativo, que deve participar de forma intensa de seu processo de aprendizagem (mediado ou não por tecnologias), enquanto reflete sobre aquilo que está fazendo.

Para que os estudantes aprendam, não basta apresentar-lhes o conteúdo. Segundo (Zabala, 1998), “[...] é necessário que, diante destes, possam atualizar seus esquemas de conhecimento, compará-los com o que é novo, identificar semelhanças, diferenças e integrá-las em seus esquemas, comprovar que o resultado tem certa coerência". Quando isso acontece, o estudante se depara com uma aprendizagem significativa. Então, a metodologia ativa é centrada no estudante, tornando sua aprendizagem protagonista, gerando interações entre professores e estudantes nas atividades acadêmicas de modo que não haja um único detentor pleno e absoluto do conhecimento. O estudante acaba promovendo sua própria aprendizagem, atuando direto no seu processo de aprendizagem e o professor assume o papel de orientador e mediador da discussão sobre a solução de problemas expostos.

As metodologias ativas dão origem a um princípio teórico significativo, a autonomia do estudante. Elas utilizam a problematização como estratégia durante o processo de ensino-aprendizagem, e conseguem motivar o estudante, pois diante do problema, ele: examina, reflete, discuti e relaciona a sua história e passa a ressignificar suas descobertas. Diante disso é necessário promover conhecimento, experimentar, inovar e usar a criatividade.

Atualmente, é necessário que os estudantes, além da aprendizagem de conteúdos, tornem-se críticos quanto à realidade social, posicionem-se, julguem e tomem decisões relacionadas ao seu convívio. Segundo a BNCC (Brasil, 2017), a Química deve atuar como um instrumento de formação humana, além de possibilitar a construção do conhecimento científico.

\subsection{Estratégias para aplicação das metodologias ativas}

As discussões acerca da utilização das metodologias ativas precisam ser baseadas em temas e tópicos de interesse para formação profissional dos estudantes, trabalhos em equipe com tarefas que exijam colaboração e participação de todos. As futuras discussões precisam ser pautadas em temas da atualidade, que promovam novas ideias, estimule a curiosidade e desperte o interesse na busca por soluções de problemas.

Uma das dúvidas que surge quando da implementação das metodologias ativas, é quanto ao tempo ou número de aulas necessário ao cumprimento da proposta. Teme-se, e com razão, o não cumprimento do programa de conteúdos previsto para a disciplina. Os padrões impostos pelo sistema educacional, de fato, não são fáceis de serem rompidos e dificultam a espontaneidade do ensino. Entretanto, conteúdos podem ser relacionados e agrupados, e um bom planejamento pode propiciar a exploração conjunta destes conteúdos por metodologias ativas. Outro aspecto que, à primeira vista pode dificultar a implementação das metodologias ativas está ligado aos padrões de avaliação comumente empregados pelas escolas. Porém, nada que o empenho e o planejamento docentes não consigam contornar.

\subsection{As metodologias ativas e o ensino de Química}

Dentro da mais moderna pedagogia, as metodologias ativas têm como objetivo o aprendizado através da vivência e experiências múltiplas e variadas, visando o desenvolvimento cognitivo, afetivo e social dos estudantes, numa visão em que educar é formar, aprender e construir seu próprio conhecimento.

Quanto ao ensino da Química, um problema bastante pertinente está associado ao desempenho não satisfatório por parte dos estudantes nesta disciplina. Além disso, o distanciamento entre a teoria e relação com o cotidiano, ou seja, a não percepção ou a não tematização desta disciplina deixa as aulas desestimuladas e sem nenhum sentido. Tornando-a por parte dos estudantes como uma disciplina difícil. Essa percepção pode estar associada a abordagens de conceitos a nível 
microscópico. Além dos conteúdos que envolvem cálculos matemáticos, que também podem não ter sido apreendidos pelos estudantes ao longo de sua jornada escolar.

Por isso, (Benedetti Filho et al. 2020, p. 581), ao citarem Oliveira, apontam que "[...] um dos fatores que eventualmente geram desinteresse pela Química é o distanciamento entre o conteúdo apresentado pelo professor e a realidade cotidiana dos estudantes, de modo que, ao longo do processo de ensino e aprendizagem, priorizam-se a memorização de leis científicas e resoluções matemáticas, estigmatizando a Química como ciência exata e em cujo contexto do ensino os professores acabam não priorizando a aplicação e a importância dessa ciência no dia-a-dia dos estudantes. "Assim, para proporcionar ambientes de aprendizagens diferentes desse contexto, "é necessário promover práticas pedagógico-didáticas ativas e construtivistas que sustentem um conhecimento coletivo e uma aprendizagem colaborativa" (Moreira et al., 2020, p. 355), proporcionando ao estudante ser mais ativo no processo de ensino-aprendizagem durante a construção do conhecimento.

De acordo com a teoria da aprendizagem de (Ausubel, 1976), sempre que a aprendizagem significativa não se efetiva, a aprendizagem mecânica acontece! E sabemos dos riscos que esta última forma de educação representa para o contexto social. Assim, na intenção de tornar o estudo da Química mais significativo, prazeroso e compreensível é preciso modificar os métodos de ensino-aprendizagem, buscando novas metodologias, novas técnicas de estudo, colocando sempre o aluno como o centro da aprendizagem. O uso da variedade na metodologia é opção do professor, contudo essa diferenciação na metodologia em sala de aula proporciona a inovação de sua prática.

A metodologia ativa tem como ponto central, segundo (Souza, Amaral \& Schimiguel, 2016), o estudante em suas múltiplas dimensões, sua estrutura global e interação com o outro. O professor como mediador do processo ensinoaprendizagem deve desenvolver competências e habilidades nos estudantes a fim de posicioná-los de forma crítica diante das situações apresentadas. A proposta da metodologia ativa é criar situações-problema que levem o aluno a pensar e relacionar o tema ao seu cotidiano (Welter et al, 2019; Soares et al., 2021).

$\mathrm{O}$ aprendizado torna-se próximo à realidade do estudante e muito mais significativo, uma vez que desperta a curiosidade em buscar novos elementos e adquirir novas perspectivas.

A utilização de novas metodologias em sala de aula traz uma maior participação dos estudantes, favorecendo a absorção e consequentemente melhorando a aprendizagem. Aprender Química requer que os estudantes sejam introduzidos numa forma diferente de pensar sobre o mundo em que vivem, interpretando e entendendo como acontecem determinadas situações a partir de seus processos. Logo, a utilização de metodologias diferenciadas em sala de aula proporciona a inovação na prática de ensino-aprendizagem. Neste contexto, (Arroio et al. 2006), destaca esta necessidade urgente do uso de metodologias alternativas eficientes voltadas para o ensino da Química que despertem o interesse dos estudantes por esta ciência.

\section{Metodologia}

A metodologia empregada neste trabalho envolveu o uso de metodologias ativas (ensino híbrido) aplicadas em turmas da $2^{\mathrm{a}}$ série do Ensino Médio de uma Escola particular de São Luís (MA).

O ensino híbrido, conforme já apresentado, é uma metodologia ativa que associa o uso da tecnologia digital com as interações presenciais e que combina atividades com e sem o professor, visando à personalização do ensino. Portanto, faz-se a combinação entre os ensinos online e presencial, favorecendo uma aprendizagem de maneira diferenciada. O ensino híbrido abre portas para o pensamento crítico, afinal o estudante tem oportunidade de compreender os objetos dos conhecimentos trabalhados de maneira mais aprofundada, além da possibilidade de abordar questões e curiosidades nos encontros presenciais.

Quanto à execução do ensino híbrido na área da Química, este pode ser realizado através de vídeo, textos, reportagens, fóruns, dentre outros, disponibilizados na internet pelo professor, com o intuito de estabelecer debates consistentes, que não extrapole o tempo da sala de aula. Deste modo, o estudante tem acesso ao conteúdo de forma antecipada, para que o tempo seja 
otimizado em sala de aula, ocorrendo um conhecimento prévio sobre quais os objetos do conteúdo a ser estudado. Portanto, se configura como uma maneira de incentivar no estudante o interesse e participação ativa pelas aulas e construção do seu conhecimento.

A metodologia ativa usada nesta estratégia teve como objetivos: estimular nos alunos a proatividade, criatividade, envolvimento nas atividades, tomada de decisões e avaliação dos resultados, com apoio de materiais didáticos. Todos os desafios e atividades propostas nas etapas do trabalho foram dosadas, planejadas, acompanhadas e avaliadas com apoio das tecnologias. Os desafios do planejado contribuiu para mobilizar as competências desejadas, intelectuais, emocionais, pessoais e comunicacionais entre os estudantes. Ademais, os estudantes foram incentivados a pesquisar, avaliar situações, pontos de vista diferente, escolhas, assumir riscos, aprender pela descoberta, caminhar do simples para o complexo, pois foram colocados diante de situações problemas reais que provavelmente serão vivenciados na vida profissional. Assim, a combinação de aprendizagem por desafios, problemas reais e trabalho em grupo pode ser considerada uma ação importante para que os estudantes aprendam fazendo e aprendam juntos.

Existem várias maneiras de avaliar uma atividade, uma possível avaliação que envolve as habilidades científicas desenvolvidas durante uma atividade, em que o estudante tem liberdade para organizar, conduzir, coletar, analisar dados e comunicar os resultados, é a utilização das rubricas. "As rubricas de avaliação descrevem os níveis de desempenho do estudante diante da realização de tarefas que exigem conhecimentos conceituais, procedimentais e atitudinais nas atividades propostas. Elas consistem em instrumentos de avaliação para professores, assim como possibilitam que os próprios alunos se auto-avaliem e entendam o que o problema proposto exige deles para sua resolução, de modo que o foco não seja apenas no resultado do experimento, mas também nos processos envolvidos" (Frazão et al., 2021, pág.4).

Ainda sobre as rubricas, (Fernandes, 2021, p. 4) elenca uma importante consideração afirmando que: “[...] embora as rubricas nos permitam avaliar, elas são descritivas e não avaliativas por natureza. Em vez de julgar o desempenho, professores e estudantes verificam qual a descrição que melhor o pode representar. Assim, antes do mais, as rubricas permitem desenvolver uma avaliação de referência criterial. E isto significa que estamos a comparar o que os estudantes sabem e são capazes de fazer num dado momento com um ou mais critérios e suas descrições e não com uma média ou com um grupo, como acontece na avaliação de referência normativa [classificatória]". As rubricas servem como feedback para um melhor acompanhamento do professor durante a execução de determinada atividade, nessa perspectiva, a avaliação funciona como uma conversa, um processo de troca entre professor e estudante, aperfeiçoando o processo de ensino-aprendizagem.

Quanto ao professor durante todo o processo, sua função foi de orientador. Já as tecnologias permitiram o registro, a visibilidade do processo de aprendizagem de cada um e de todos os envolvidos, além de mapear os progressos, apontar as dificuldades e prever novos caminhos com dificuldades específicas (plataformas adaptativas).

\subsection{Estratégias, competências, habilidades e sequência didática}

Para essa estratégia foi desenvolvido a metodologia ativa - ensino híbrido. Nessa metodologia foi abordado o tema petróleo como objeto de conhecimento.

A sequência didática foi organizada e elaborada em cinco momentos, alternados entre as modalidades on-line e presencial, utilizando como base teórico-metodológica o método instrucional 5E (Bybee et al, 2006; Patro, 2008). Tal método é caracterizado pelas seguintes fases:

1. Engajamento (apresentação inicial do tema aos estudantes, em uma abordagem motivadora);

O trabalho foi iniciado com a apresentação de um questionário sobre o petróleo. Esse questionário foi encaminhado via plataforma Eduqo e respondida totalmente on-line pelos estudantes e continha questões do tipo:

a. O que é gasolina? 
b. Em que situações a gasolina afeta a sua vida? Dê exemplos.

c. Você sabe a origem e as principais características da gasolina? Comente.

d. Em que situações do seu cotidiano a gasolina é usada? Dê exemplo e comente.

e. Você consegue relacionar a gasolina com aspectos sociais, econômicos e ambientais? Dê exemplos.

f. Imagine um mundo alternativo onde não exista gasolina. O que seria diferente neste mundo em relação ao nosso?

2. Exploração (aprofundamento pelos estudantes nas questões fundamentais, a partir da relação com outros contextos);

Nessa etapa também de forma on-line, foram enviados links de reportagens para os estudantes que relacionam o tema a ser estudado com situações atuais na área ambiental, científica, econômica, histórica e social. Esses links foram encaminhados aos estudantes via plataforma Eduqo e após a leitura dos textos foi realizado em sala de aula presencial um debate sobre as reportagens. Para esse momento, as reportagens utilizadas foram:

a. Petrobras anuncia alta da gasolina e do diesel em venda nas refinarias - http://g1.globo.com/economia/seudinheiro/noticia/2014/11/petrobras-anuncia-aumento-da-gasolina.html

b. Qual é o combustível que mais polui a atmosfera? - http://www.brasilescola.com/quimica/qual-combustivel-que-maispolui-atmosfera.htm

c. Sustentabilidade - http://aplicativos.grupopaodeacucar.com.br/pao/sustentabilidade/gasolina-ou-alcool-qual-e-melhorpara-o-meioambiente/

d. Haverá o terceiro choque? - http://www1.folha.uol.com.br/folha/dinheiro/petroleo_choque.shtml

3. Explicação ( $\mathrm{O}$ professor apresenta novos elementos aos estudantes, relacionados principalmente ao conhecimento científico);

Nesse momento, os estudantes foram divididos em cinco grupos, e cada grupo ficou responsável por pesquisar e elaborar uma apresentação no formato seminário (trabalho em grupo) a partir dos temas abaixo:

a. Processos de obtenção;

b. Refino do petróleo;

c. Utilização dos subprodutos do petróleo;

d. Petróleo nos dias atuais;

e. Petróleo e o meio ambiente.

4. Elaboração (Nessa etapa deve ocorrer a construção do conhecimento por parte dos estudantes);

Nesse momento, de forma presencial, os grupos realizaram um debate, apresentando o trabalho elaborado a partir do tema sorteado. Cada equipe teve um tempo fixo para fazer a socialização dos alcances do trabalho e debater com as demais equipes.

5. Exame (momento em que se avaliam as construções realizadas pelos estudantes).

Cada um dos momentos acima foi acompanhado e avaliado pelo professor, cada aluno teve sua nota baseando-se no comprometimento com o trabalho, engajamento, participação e organização em cada uma das etapas do trabalho.

As seguintes competências foram trabalhadas: apropriação da cultura digital; trabalho em equipe; resolução de problemas; desenvolvimento de ideias, reflexões e tomada de decisão; comunicação; liderança; argumentação oral; criatividade; troca de informações e desenvolvimento da capacidade crítico-argumentativo. Em termos de habilidades, podem 
ser citadas: (EM13CNT301) construir questões, elaborar hipóteses, previsões e estimativas, empregar instrumentos de medição e representar e interpretar modelos explicativos, dados e/ou resultados experimentais para construir, avaliar e justificar conclusões no enfrentamento de situações-problema sob uma perspectiva científica; (EM13CNT302) comunicar, para públicos variados, em diversos contextos, resultados de análises, pesquisas e/ou experimentos, elaborando e/ou interpretando textos, gráficos, tabelas, símbolos, códigos, sistemas de classificação e equações, por meio de diferentes linguagens, mídias, Tecnologias Digitais de Informação e Comunicação (TDIC), de modo a participar e/ou promover debates em torno de temas científicos e/ou tecnológicos de relevância sociocultural e ambiental.

\section{Resultados e Discussão}

A utilização das metodologias ativas requer um planejamento detalhado, por parte do professor, ainda maior do que para as aulas tradicionais. É necessário que o professor tenha bastante clareza dos objetivos que pretenda alcançar, bem como das estratégias de acompanhamento, conhecendo os pontos positivos e negativos de cada uma das etapas das atividades proposta, com o intuito de não tornar o momento da aula em um desânimo e perda de motivação por parte dos alunos.

Há vantagens no ensino híbrido em que o equilíbrio entre o acompanhamento direto do professor e a liberdade do aluno conduzir sua aprendizagem pode ser alcançado. Assim, não convém substituir, por simples estratégia, as aulas presenciais por remotas. Elas podem acontecer de forma intercaladas dando mais segurança aos estudantes.

Durante a execução da sequência são sugeridas atividades para os estudantes que utilizam diferentes tipos de materiais como: vídeo, construção de mapa mental, reportagens e exercícios. O estudante é incentivado a participar durante todo o tempo, seja respondendo perguntas, participando de atividades em equipes, socializando conteúdos e discutindo a respeito de temas interdisciplinar com o assunto estudado possibilitando uma participação mais ativa por parte do estudante na construção do seu aprendizado.

As discussões levantadas em sala foram gravadas e transcritas em dois grupos, falas dos estudantes (E) e a fala do professor (P), o qual acompanhou todas as ações, sem realizar intervenções desnecessárias, sempre estimulando a autonomia dos estudantes.

\subsection{Engajamento}

Esta fase durou 45 minutos de discussão e problematização do tema com os estudantes. Foram realizadas discussões sobre petróleo e derivados, notadamente a gasolina, bem como a relação destes materiais com a ciência, a tecnologia e sociedade. A princípio não tem uma questão problema, o foco dessa etapa é conhecer o que os estudantes sabem sobre o assunto e sua relação direta com a sociedade que ele está inserido. Os alunos responderam a um questionário e, ao analisar a aula transcrita, observa-se que a maioria dos estudantes consegue estabelecer uma relação do conteúdo petróleo com CTS, de maneira a perceber o grande impacto que o petróleo tem com as situações reais que acontecem diariamente no cotidiano, como isso tem um impacto não só na sociedade, mas no meio ambiente e nos outros países. Algumas falas dos estudantes podem ser destacadas:

P - "Qual a importância da gasolina para vocês?"

E - "Sem a gasolina nem viríamos pra escola."

$\mathrm{P}$ - "O petróleo é elemento de conflito entre países?"

E - “A Venezuela ta em crise por causa do petróleo."; “Por causa do petróleo que ta tendo guerra no Oriente.”... 
Em todo o momento da aula é possível observar a participação dos estudantes, buscando explicações para questões contemporâneas e que permeiam as colunas dos jornais. Todas essas possíveis respostas são aceitáveis, pois se tratam do conhecimento que eles trazem para o encontro, o seu ponto de partida, a partir do qual novos conhecimentos poderão ser ancorados. O Quadro 1 resume as rubricas referentes a esta fase.

Quadro 1 - Rubricas referentes à fase 1 (engajamento).

\begin{tabular}{|c|c|c|c|}
\hline Critérios & Avançado & Suficiente & Razoável \\
\hline Engajamento & $\begin{array}{l}\text { Mencionou novos conceitos, } \\
\text { consegui relacionar o tema } \\
\text { com situações do cotidiano } \\
\text { e com os acontecimentos } \\
\text { nos mundo, buscou } \\
\text { posteriormente diferentes } \\
\text { fontes e recursos. Trouxe } \\
\text { relatos, curiosidades e dados } \\
\text { estatísticos atuais. }\end{array}$ & $\begin{array}{l}\text { Mencionou } \\
\text { importantes sobre o tema, } \\
\text { faltou um pouco mais de } \\
\text { aprofundamento do tema, } \\
\text { posteriormente usou poucas } \\
\text { fontes de referência e deixou } \\
\text { de enriquecer sua produção } \\
\text { com curiosidades. }\end{array}$ & $\begin{array}{l}\text { Mencionou pontos } \\
\text { abordados em sala de aula } \\
\text { sobre o tema em questão, } \\
\text { trouxe apenas informações } \\
\text { que já conhecia, baseados } \\
\text { em senso comum. Não teve } \\
\text { uma participação tão } \\
\text { efetiva. }\end{array}$ \\
\hline Pontuação & 0,3 & 0,2 & 0,1 \\
\hline Participação (\%) & 75 & 20 & 5 \\
\hline
\end{tabular}

Fonte: Autores (2021).

\subsection{Exploração}

O segundo encontro durou também aproximadamente 45 minutos de discussão e problematização com os estudantes sobre as reportagens e matérias indicadas para o momento. Após a leitura dos textos foi realizado em sala de aula presencial um debate sobre os conteúdos das reportagens, bem como matérias e vídeos pesquisados por eles mesmos. Eles passaram a conhecer melhor a matriz energética nacional, bem como as vantagens e desvantagens dos usos de gasolina e álcool.

Pela transcrição realizada, observa-se uma maior participação e interação da turma nesta etapa que na anterior, visto que os mesmos já tinham um conhecimento prévio do tema e foram adicionados novos conhecimentos. Ocorreu também uma maior interação entre os estudantes e suas falas estavam mais cheias de convicção e tinham propriedades no que estavam discutindo. Como nessa etapa os estudantes foram incentivados a fazer pesquisas sobre o tema, evidenciou-se a característica de uma fase investigativa por parte dos estudantes, proporcionando-lhes um maior contato com a ciência e sua relação com a sociedade e o meio ambiente. No Quadro 2 estão apresentadas análises deste momento

Quadro 2 - Rubricas referentes à fase 2 (exploração).

\begin{tabular}{|c|c|c|c|}
\hline Critérios & Avançado & Suficiente & Razoável \\
\hline Exploração & $\begin{array}{l}\text { Mencionou novos conceitos } \\
\text { pesquisados autonomamente } \\
\text { com os que já abordados } \\
\text { nos momentos anteriores da } \\
\text { disciplina, buscou diferentes } \\
\text { fontes e recursos. Trouxe } \\
\text { relatos, curiosidades e dados } \\
\text { estatísticos atuais. }\end{array}$ & $\begin{array}{l}\text { Mencionou pontos } \\
\text { importantes das leituras } \\
\text { complementares sobre o tema, } \\
\text { faltou um pouco mais de } \\
\text { aprofundamento do tema, } \\
\text { você usou poucas fontes de } \\
\text { referência e deixou de } \\
\text { enriquecer sua produção com } \\
\text { curiosidades. }\end{array}$ & $\begin{array}{l}\text { Mencionou pontos } \\
\text { abordados em sala de aula } \\
\text { sobre o tema em questão, } \\
\text { trouxe apenas informações } \\
\text { de uma única fonte ou } \\
\text { apenas trouxe dados } \\
\text { baseados em senso comum. } \\
\text { Sua produção não teve } \\
\text { caráter científico. }\end{array}$ \\
\hline Pontuação & 0,3 & 0,2 & 0,1 \\
\hline Participação (\%) & $87 \%$ & $9 \%$ & $4 \%$ \\
\hline
\end{tabular}

Fonte: Autores (2021). 


\subsection{Explicação}

A terceira aula durou também aproximadamente 45 minutos de discussão entre os estudantes, com presença mais direta do professor. Os alunos foram divididos em equipes e cada equipe ficou com um tema. Os estudantes ficaram responsáveis por elaborar uma apresentação de acordo com o tema sorteado. Cada estudante tinha uma função definida na equipe, de modo que todos pudessem colaborar para o desenvolvimento do trabalho.

Pelas transcrições das falas, observa-se que os alunos recorreram aos materiais apresentados na etapa anterior, agora realizando leituras com mais atenção e profundidade. Daí a importância de se escolher textos que apresentem o contexto social, político e econômico, mas que permitam considerações científicas. Nesta fase os estudantes manifestaram habilidades até então escondidas que evidenciaram o quanto a abordagem do conteúdo estava fazendo sentido na relação com outras situações reais. No quadro 3 estão apresentadas as considerações sobre as rubricas para este momento.

Quadro 3 - Rubricas referentes à fase 3 (explicação).

\begin{tabular}{|c|c|c|c|}
\hline Critérios & Avançado & Suficiente & Razoável \\
\hline Explicação & $\begin{array}{l}\text { Há sustentação das ideias na } \\
\text { forma como foram escritas, } \\
\text { escrita clara e sem } \\
\text { ambiguidade. Evidência de } \\
\text { opiniões originais e } \\
\text { pessoais, com ideias } \\
\text { inovadoras. }\end{array}$ & $\begin{array}{l}\text { Pouca sustentação das ideias } \\
\text { na forma como foram escritas. } \\
\text { Evidência de opiniões } \\
\text { originais e pessoais, mas } \\
\text { apenas com relação ao } \\
\text { conteúdo apresentado, sem } \\
\text { ideias inovadoras. }\end{array}$ & $\begin{array}{l}\text { Não há sustentação das } \\
\text { ideias na forma como } \\
\text { foram escritas. Evidência } \\
\text { de opiniões originais e } \\
\text { pessoais, sem ideias } \\
\text { inovadoras. }\end{array}$ \\
\hline Pontuação & 0,3 & 0,2 & 0,1 \\
\hline Participação (\%) & $82 \%$ & $11 \%$ & $7 \%$ \\
\hline
\end{tabular}

Fonte: Autores (2021).

\subsection{Elaboração}

A quarta aula durou também aproximadamente 45 minutos e foram destinados a sistematizar a unidade didática, Nesse momento, formato presencial, os grupos realizaram um debate com a turma apresentando os trabalhos construídos em Equipe, a partir do tema sorteado.

Durante toda a socialização foi possível concluir que boa parte dos estudantes conseguiu compreender o conteúdo e relacionar com questões científicas, históricas, sociais, políticas e ambientais. Os estudantes conseguiram justificar suas falas, desenvolvendo um raciocínio lógico sobre os conteúdos trabalhados durante as aulas anteriores. A justificativa durante as falas e discussões entre os estudantes demonstra a segurança ao elaborarem respostas e debaterem os temas levantados durante as aulas. Segundo (Sasseron, 2008), a justificativa aparece e tem maior convicção quando em uma afirmação qualquer proferida, lança-se mão de uma garantia para o que é proposto; isso faz com que a afirmação ganhe reconhecimento, tornando mais segura. O quadro a seguir, Quadro 4, estão resumidas anotações sobre as rubricas desta fase. 
Quadro 4 - Rubricas referentes à fase 4 (elaboração).

\begin{tabular}{|c|c|c|c|}
\hline Critérios & Avançado & Suficiente & Razoável \\
\hline Elaboraçãao & $\begin{array}{l}\text { Adequados e que permite ao } \\
\text { leitor focar-se na } \\
\text { mensagem. Todas as } \\
\text { informações estão corretas e } \\
\text { a terminologia utilizada é } \\
\text { adequada ao tema. }\end{array}$ & $\begin{array}{l}\text { Poucos erros, mas ainda } \\
\text { permite ao leitor focar-se na } \\
\text { mensagem. As informações } \\
\text { estão corretas, mas há uma } \\
\text { imprecisão nos usos de termos } \\
\text { e expressões com relação ao } \\
\text { tema. }\end{array}$ & $\begin{array}{l}\text { Muitos erros que levam o } \\
\text { leitor a se perder no } \\
\text { contexto da mensagem. } \\
\text { Muita linguagem coloquial } \\
\text { e sem fundamentação } \\
\text { teórica. }\end{array}$ \\
\hline Pontuação & 0,3 & 0,2 & 0,1 \\
\hline Participação (\%) & $82 \%$ & $11 \%$ & $7 \%$ \\
\hline
\end{tabular}

Fonte: Autores (2021).

\subsection{Exame (Avaliação)}

A fase cinco, a avaliação, é concebida como um processo, ou seja, avaliação para a aprendizagem, e não avaliação da aprendizagem. Diante disso, durante toda a execução da sequência didática houve intervenções e mediações referentes à construção do conhecimento no momento em que os estudantes praticam a atividade idealizada pelo professor (Batista \& Bezerra, 2020).

Segundo (Ralph Tyler, 1974) o processo de avaliação consiste essencialmente em determinar em que medida os objetivos são realmente alcançados pelo programa do currículo e do ensino. Avaliar não é a última etapa. Identificar os conceitos construídos pelos estudantes em seu cotidiano sobre o tema a ser trabalhado é o ponto de partida da ação educativa; durante o processo, foram analisados os avanços conceituais dos estudantes; ao final de cada etapa do processo é o momento de verificar se os objetivos de aprendizagem foram atingidos. Nesse percurso, idas e vindas acontecem o tempo todo, replanejando a ação educativa, acertando os rumos a serem tomados, retomando o que for necessário para todo o grupo ou para alguns estudantes.

\section{Conclusão}

Os resultados revelam que o uso das metodologias ativas estimula a participação dos estudantes, contribuindo de forma mais positiva para uma aprendizagem significativa e dinâmica. Os estudantes desenvolveram raciocínio crítico e reflexivo, habilidades, competências e melhoria na tomada de decisão ao realizarem trabalho em grupo. Observou-se que a percepção dos estudantes quanto à utilização das metodologias ativas na disciplina de química facilitou o aprendizado, demonstrando um interesse maior comparado ao que se percebe na abordagem tradicional.

A utilização da metodologia ativa na disciplina permitiu aos estudantes, uma maior compreensão dos conteúdos abordados, mais interação, maior autonomia e motivação. É importante pontuar a conexão entre o ensino tradicional e as práticas de metodologias ativas, tendo em vista que por meio delas pode-se notar um aprimoramento no processo de ensinoaprendizagem baseando-se na construção do conhecimento, promovendo resultados mais significativos aos estudantes.

As atividades de cunho argumentativo possibilitam o estudante em articular saberes, com o intuito de elaborar justificativas baseadas no conhecimento científico que possa dar mais respaldos na argumentação de um ponto de vista, na resolução de uma situação-problema. Ao expor seus argumentos, o estudante traz para sala de aula o entendimento que tem da situação em questão. 


\section{Agradecimentos}

Os autores agradecem ao Programa de pós Graduação em Ensino de Ciências e Matemática pelo apoio no desenvolvimento deste trabalho.

\section{Referências}

Arroio, A., Honório, K. M., Weber, K. C., Mello, P. H-., Gambardella, M. T. P., \& Silva, A. B. F. (2006). O Show da Química: Motivando o Interesse Científico. Química Nova, 29, 173-178.

Ausubel, D. P. (1976). Psicología educativa. Un punto de vista cognoscitivo. Ed. Trillas.

Basso, M. (2017). Como no século 19: nossas salas de aula pararam no tempo. https://www.gazetadopovo.com.br/educacao/como-no-seculo-19-nossas-salasde-aula-pararam-no-tempo-arjn56m7xzsmdid2inpnhu8cv/

Batista, W. M. \& Bezerra, C. W. B. (2020). O currículo e o ensino de ciências na educação básica: uma leitura da BNCC. Mens Agitat, 15, 90-102.

Beck, C. (2007). Andragogia Brasil: Como aprender a aprender? https://andragogiabrasil.com.br/como-aprender-a-aprender/

Benedetti Filho, E., Cavagis, A. D. M., \& Benedetti, L. P. S. (2020). Jogo didático de cartas para revisões conceituais no ensino de Química Orgânica. Experiências em Ensino de Ciências, 15(3), 580-590

Brasil (2017). Ministério da Educação. Base Nacional Comum Curricular.

Bybee, R. W., Taylor, J. A., Gardner, A., Van Scotter, P., Powell, J. C., Westbrook, A., \& Landes, N. (2006). The BSCS 5E Instructional Model: Origins and Effectiveness. Ed. BSCS.

Fernandes, D. (2021). Rubricas de Avaliação. Folha de apoio à formação - Projeto de Monitorização, Acompanhamento e Investigação em Avaliação Pedagógica (MAIA). Ministério da Educação/Direção-Geral da Educação.

https://afc.dge.mec.pt/sites/default/files/202104/Folha\%205_Rubricas\%20de\%20Avalia\%C3\%A7\%C3\%A3o.pdf.

Frazão, L. S., Gusmão, M. S. S., Antunes, E. P. (2021). Atividades experimentais investigativas e a habilidade de elaborar hipóteses na formação inicial de professores. Research, Society and Development, 10, 1-16.

Moran, J. (2014). Novos modelos de sala de aula. Educatrix, 7, 37 - 33.

Moran, J. (2018) Metodologias ativas para uma aprendizagem profunda. In: MORAN, José, BACICH, Lilian (Org.). Metodologias ativas para uma educação inovadora: uma abordagem teórico-prática. Ed.: Penso.

Moreira, J. A., Henriques, S., \& Barros, D. M. (2020). Transitando de um ensino remoto emergencial para uma educação digital em rede, em tempos de pandemia. Dialogia, 34, 351-364.

Patro, E. T. (2008) Teaching Aerobic Cell Respiration Using the 5 Es. The American Biology Teacher, 70, 85-87.

Sasseron, L. H., \& Carvalho, A. M. P. (2008). Almejando a Alfabetização Científica no Ensino Fundamental: A proposição e a procura de indicadores do processo. Investigações em Ensino de Ciências, 13, 333-352.

Silva, M. R. (2008). Currículo e Competências: a formação administrada. Ed. Cortez.

Silva, V. J. M. O., Schneider, M. C., Cezere, M. L. S., Martins, S. N., \& Forneck, K. L. (2020). Aprendizagem colaborativa com world café: uma experiência dessa parceira em sala de aula. Research, Society and Development, 9, 1-17.

Soares, M. S., Mauriz, T. R. M., Ayres, M. C. C., Silva, J. S., Costa, C. R. M., Lima, J. F.., Lavor, C., Lima, G. F., Vieira, D. F., \& Moura, L. F. W. G. (2021).

O uso de metodologias ativas de ensino por professores de Ciências nas escolas de Angical - PI. Research, Society and Development, $10,1-11$.

Souza, E. C., \& Amaral, L. H., Schimiguel, J. (2016). Tecnologias Digitais e Ensino a Distância: Pesquisa e Inovação no ensino superior. Terracota Ed.

Tyler, R. W. (1974). Princípios básicos de currículos e ensino. Ed. Globo.

Welter, R. B., Foletto, D. S., \& Bortoluzzi, V. I. (2019). Metodologias ativas: uma possibilidade para o multiletramento dos estudantes. Research, Society and Development, $9,1-21$

Zabala, A. (1998). A prática educativa: como ensinar. Ed. Artmed. 